\title{
In Situ Non-invasive Soil Carbon Analysis: Sample Size and Geostatistical
}

Considerations.

Lucian Wielopolsk

Brookhaven National Laboratory, Environmental Sciences Department, Upton, NY

11973

Correspondence address: Lucian Wielopolski, Brookhaven National Laboratory, Environmental Sciences Department, Bldg. 490-D, Upton, NY 11973. Tel: (631) 3443656, Fax: (631)344-7244, E-mail: 1wielo@bnl.gov

\section{Abstract}

Key Words: Soil, carbon sequestration, neutrons, MCNP

\section{Introduction}

The consequences of global warming, promoted by anthropogenic $\mathrm{CO}_{2}$ emissions into the atmosphere, are partially mitigated by the photosynthesis of terrestrial ecosystems that act as an atmospheric $\mathrm{CO}_{2}$ scrubber, thereby sequestering carbon below ground, in the topsoil, and in the above-ground litter and vegetation. Soil carbon sequestration is one of several programs that encompass the study of point-source capture from industrial activities, $\mathrm{CO}_{2}$ conversion, and storage in geological formations and in the oceans. Sequestration in terrestrial ecosystems, albeit being recognized as a short-term solution, provides an immediate low-cost solution. Soil carbon sequestration includes planting trees, employing no-till farming, preserving forests, reclaiming land, and other agricultural practices. Carbon sequestration also is promoted by putting forward a system for national and international "carbon credits" that can be negotiated and traded between $\mathrm{CO}_{2}$ producers and sequesters. 
A central theme of research on the terrestrial carbon sequestration over the last decade evolved around the recognition that there is a large terrestrial sink for the atmospheric $\mathrm{CO}_{2}$ [Sarmiento and Wofsy, 19991. The magnitude of this sink was estimated to be on the order of $1.5 \pm 1.0 \mathrm{Gt} \mathrm{C/yr}$ for $1980-1989$ [Schimel et al. 19961, and as having increased to $>2.5 \mathrm{Gt} \mathrm{C} / \mathrm{yr}$ in the last decade, which is about $25 \%$ of the annual $\mathrm{CO}_{2}$ emission into the atmosphere. Thus, the potential consequences of the steady increase in atmospheric emissions are partially mitigated by photosynthesis in plants that removes $\mathrm{CO}_{2}$ from the atmosphere and sequesters it in soil. The corollary benefits of carbon sequestration are the increased quality and fertility of the soil, and a reduction in erosion. In addition, under private emission- trading strategy, farmers would be able to sell carbon "credits" to a $\mathrm{CO}_{2}$ emitting industry. Estimates of this market in the United States are about \$1-5 billions per year for the next 30-40 years [Rice, 20041. These two issues, namely carbon sequestration, and trade with carbon "credits", require the development of novel non-destructive instrumentation to facilitate a better understanding of the belowground carbon processes, while at the same time providing a direct quantitative measure or an index of the belowground carbon stores for the carbon "credit" trade.

Current standard method for quantifying carbon in soil involves extracting a core and analyzing samples from it [Taylor et. al., 19911. This traditional approach is labor intensive, slow, destructive, and, consequently, very limited in its utility and scope. Three newly emerging methods to measure carbon in soil in situ are a Laser Induced Breakdown Spectroscopy (LIBS) [Cramers et al., 2001], near- and mid-infi-ared spectroscopy [McCarty et al., 20021, and Inelastic Neutron Scattering (INS) method [Wielopolski et.al., 20041. While the first two methods present improvements over traditional core sampling, 
both are destructive. In the first case, small volumes of about 50 micro-liters from an extracted core are vaporized, and the spectral emission is measured. In the second case, a sensor mounted on a tip of a shank ploughs through the soil at a set depth and senses the carbon to a depth of few millimeters. The third, INS, method is based on fast neutron scattering and concurrent measurement of characteristic gamma rays induced in carbon. This process is denoted as ${ }^{12} \mathrm{C}\left(\mathrm{n}, \mathrm{n}^{\prime}, \gamma\right){ }^{12} \mathrm{C}$, in which $\mathrm{n}$ and $\mathrm{n}^{\prime}$ are the incident- and scattered- neutrons, respectively [Wielopolski et al., 2000: Wielopolski et al., 20031. The INS method is nondestructive and can be used repetitively for measurements at exactly the same spot over extended periods, or alternatively, employed in a continuous scanning mode over large areas. The basic methodology and its use were described by Csikai, [1987] and by Nargolwalla and Przybylowicz, (19731, respectively. An INS system to measure carbon in soil was reported by Wielopolski et al., [2004]. The INS system with its calibration and attributes are briefly described in the subsequent sections with special attention to the distinctly large volumes it can measure.

\section{Attributes of the INS System}

The INS system consists of a neutron generator (NG), an electrical device that can generate neutrons based on the $(\mathrm{d}, \mathrm{t})$ reaction, a shadow shielding placed between the NG and the detectors, and a NaI scintillation detection system. The original INS system was calibrated by placing the NG and the detection assembly directly on the soil in a sandpit filled with a homogeneous mixture of sand and carbon at $0,2.5,5$, and 10 percent by weight. This setup, shown in Fig. 1, generated the calibration line presented in Fig. 2 
[Wielopolski et. al., 20041. The current field-deployable INS system was modified to include three detectors instead of one, and mounted on a stand at about $30 \mathrm{~cm}$ above the ground. The height of the stand was optimized to maximize the carbon signal's yield and was designed to accommodate the various residues left on the ground in no-till fields thus making it suitable as a field-scanning system when mounted on a mobile cart; the new setup is shown in Fig. 3. The new system's configuration improved the sensitivity to carbon by a factor of 7.3, with a concurrent increase in the background by $\mathbf{6 . 2}$, thus improving its overall performance by about a factor of 3 (7.3/sqrt(6.2)).

Based on the calibration shown in Fig. 2, the INS results were compared with those fi-om chemical analysis of the top $5 \mathrm{~cm}$ of core samples taken from different sites; the findings are summarized in Table 1. It is important to point out that all the results are expressed in terms of carbon density ( $\mathrm{g} \mathrm{C/cc)}$ because the INS instrument basically "sees" a constant volume, making the carbon signal proportional to the number of carbon atoms present in that volume.

Table 1. Comparison of INS results versus chemical analysis of the top $5 \mathrm{~cm}$ of soil.

INS gC/ce

Pine Stand (w,l)
Pine Stand (w/o,l)
Oak Forest (w/o,l)
Sand Patch
Sandy Soil
Sand Pit $($ Cal $)$

$$
\begin{aligned}
& \mathbf{0 . 0 9 9} \pm \mathbf{0 . 0 0 5} \\
& \mathbf{0 . 0 7 9} \pm \mathbf{0 . 0 0 5} \\
& \mathbf{0 . 0 7 2} \pm \mathbf{0 . 0 0 4} \\
& \mathbf{0 . 0 2 6} \pm \mathbf{0 . 0 0 3} \\
& \mathbf{0 . 0 9 1} \pm \mathbf{0 . 0 0 7}
\end{aligned}
$$$$
0.0
$$

Chem. Analysis Mean gC/cc

$\mathbf{0 . 0 7 3} \pm \mathbf{0 . 0 2 1}$

$0.085 \pm 0.017$

$\mathbf{0 . 0 2 5} \pm \mathbf{0 . 0 0 2}$

$\mathbf{0 . 1 0 4} \pm 0.019$

$0.0004 \pm$
Ratio

1.082

0.847

1.040

0.875

The INS results in Table 1 can be expressed mathematically as an integral of carbon concentration, $\mathrm{C}_{\mathrm{c}}(\mathrm{x}, \mathrm{y}, \mathrm{z})$, with a weight function, $\mathrm{w}(\mathrm{x}, \mathrm{y}, \mathrm{z})$, that depends on the distribution 
of neutron flux , the reaction rates, the gamma-ray yield, and the efficiency of gamma ray counting. Thus, in general, the carbon yield can be expressed as

$$
C_{Y}=k \iiint C_{c}(x, y, z) w(x, y, z) d x d y d z
$$

where $\mathrm{k}$ is a proportionality constant and the integration is carried out over the volume seen by the detectors. When the profile of carbon depth is constant, i.e., uniformly distributed with depth, Eq. 1 simplifies to represent the mean value for carbon multiplied by the integrated transfer function of the system. Remember that, by definition, the mean value of carbon concentration in soil is an imaginary value, such that if it had been uniformly distributed in a given volume it would yield the same amount of total carbon as the true distribution in that volume. Thus, in general, the weighted mean of a soil carbon is given in Eq. 2:

$$
M_{\mathrm{Cc}}=\frac{\iiint \mathbf{C}_{\mathrm{c}}(\mathbf{x}, \mathbf{y}, \mathbf{z}) \mathrm{w}(\mathbf{x}, \mathbf{y}, \mathbf{z}) \mathbf{d x d y d z}}{\iiint d x d y d z}
$$

where $\mathrm{M}_{\mathrm{Cc}}$ is the weighted mean carbon concentration, $\mathrm{C}$, is its spatial distribution, and the integration is performed over the entire volume of interest. Since the system sees a constant volume combining Eqs. 1 and 2, its response can be calibrated in terms of the mean carbon concentration. Clearly, this calibration depends on the carbon profile in the 
soil, so that further investigation is needed about the sensitivity of the calibration to the variations in the profile's parameters. The significance of this calibration increases with an increase in the sampled volume, which is relatively large, hundreds of liters, for the INS system.

The volume sampled by the INS system is defined by the intersection of the space irradiated by neutrons with that subtended by the solid angle of the detectors. Because of the propagation of the nuclear radiation, this space is semi-infmite, however, for any practical purposes 90 or 95 percent of the signal is derived from a finite sample size. To assess the size of that volume, a Monte Carlo Neutron Photon (MCNP) probabilistic transport code [Breismeister, 1993, Wielopolski et. al., In Press] first was applied to estimate the volume in soil in which the neutron flux is reduced to the $50 \%$ and $10 \%$ level; these volumes were 11.5 and 277 liters, and assuming a soil bulk density of $1.4 \mathrm{~g} / \mathrm{cc}$, they correspond to 17.5 and $416 \mathrm{~kg}$, respectively. Fig. 5 shows the neutron isoflux distribution in soil, with a projection of specific isoflux contours in Fig. 6.

An additional consequence of sampling large volumes of soil and, in particular, with a large footprint, such as that of the INS system, is the averaging effect on the lateral variability of the carbon distribution. Although spatial- and temporal-heterogeneities of infield measurements are well recognized, these are minimized or ignored on the account of normal statistics, i.e., it is assumed that i) the observations are spatially or temporarily independent of each other, and, ii) the mean values are based on normally distributed sets of observations. However, the validity of these two assumptions is seldom investigated. The largeness of the sampled volume also affects error propagation in estimates of the field parameters, thus affecting the number of samples required for a desired level of confidence 
in the estimates. For example, ten thousands points, representing carbon atoms in a unit volume, uniformly distributed in space and normally distributed with depth are shown in Figs. 7 and 8, respectively. The sampling volume is denoted in these figures by a yellow cube centered in each panel. After uniformly sampling these two distributions with a variable cube size, i.e., a variable sampling volume, the estimated mean values of the number of points encountered inside the sampling volume in 100 samples randomly drawn from each population differ significantly. For the uniform distribution, the mean value fluctuates around the true mean, while it is biased for the normal distribution. Similarly, the estimated SD for each population differs markedly with an increase in the sampled volume. For a uniform distribution the SD monotonically decreases, while for the normal distribution, it remains approximately constant. The results of these simplified simulations are shown in Figs. 9 and 10.

\section{Summary}

I discuss a new approach for quantitative carbon analysis in soil based on INS. Although this INS method is not simple, it offers critical advantages not available with other newly emerging modalities. The key advantages of the INS system include the following: 1) It is a non-destructive method, i.e., no samples of any kind are taken. A neutron generator placed above the ground irradiates the soil, stimulating carbon characteristic gamma-ray emission that is counted by a detection system also placed above the ground. 2) The INS system can undertake multielemental analysis, so expanding its usefulness. 3) It can be used either in static or scanning modes. 4) The volume sampled by 
the INS method is large with a large footprint; when operating in a scanning mode, the sampled volume is continuous. 5) Except for a moderate initial cost of about $\$ 100,000$ for the system, no additional expenses are required for its operation over two to three years after which a NG has to be replenished with a new tube at an approximate cost of $\$ 10,000$, this regardless of the number of sites analyzed.

In light of these characteristics, the INS system appears invaluable for monitoring changes in the carbon content in the field. For this purpose no calibration is required; by establishing a carbon index, changes in carbon yield can be followed with time in exactly the same location, thus giving a percent change. On the other hand, with calibration, it can be used to determine the carbon stock in the ground, thus estimating the soil's carbon inventory. However, this requires revising the standard practices for deciding upon the number of sites required to attain a given confidence level, in particular for the purposes of upward scaling. Then, geostatistical considerations should be incorporated in considering properly the averaging effects of the large volumes sampled by the INS system that would require revising standard practices in the field for determining the number of spots to be sampled.

It is highly desirable to assess properly the sampled volume for reporting the absolute value of the measured carbon. At the same time, increasing the number of detectors surrounding the NG can reduce error propagation. In the present work, only the volume irradiated by the neutrons was estimated. It should be pointed that the carbon yield is also affected by the neutron energy spectrum that changes with depth. Thus, all these considerations must be considered carefully when evaluating the detectors' configuration and the resulting counting efficiency. 
In summary, INS system is a novel approach for non-destructive carbon analysis in soil with very unique features. It should contribute in assessing soil carbon inventories and assist in understanding belowground carbon processes. The complexity of carbon distribution in soil requires a special attention when calibrating the INS system, and a consensus developed on the most favorable way to report carbon abundance. Clearly, this will affect the calibration procedures.

\section{Acknowledgement}

This work was supported by the U.S. Department of Energy under contract No. DE-AC0298CH 10886.

\section{References}

Breismeister JF., (1993), ed. "MCNP-A General Purpose Monte Carlo N-Particle Transport Code Version 4A." Los Alamos National Laboratory, NM, LA-12625M.

Cramers DA., Ebinger MH., Breshears DD., Unkefer PJ., Kammerdiener SA, Ferris MJ., Catlett KM., and Brown JR., (2001), Measuring Total Soil Carbon with LaserInduced Breakdown Spectroscopy(LIBS). J. Environ. Qual., 30 pp 2202-2206. Csikai J., (1987), CRC Handbook of Fast Neutron Generators V1. CRC Press, Inc Boca Raton, Florida. 
Dane JH., and Topp GC., (eds), (2002), Methods of Soil Analysis: Part 4 - Physical

Methods. Agron. Monogr. 5. Soil Science Society America, Inc. Madison, WI. McCarty GW., Reeves III JB., Reeves VB Follett RF., and Kimble JM., (2002) Mid$\infty$

Infrared and Near-Infrared Diffuse Reflectance Spectroscopy for Soil Carbon

Measurement, Soil Sci. Soc. Am. J., 66 pp 640-646.

Nargolwalla SS., and Przybylowicz EP., (1973), "activation Analysis with Neutron

Generators.” John Wiley \& Sons, New York/London/Sydney/Toronto.

Rice CW., (2004), Background, http://www.casmgs.colostate.edu, A CASMGS Forum,

Texas A\&M University, Bryan-Collage Station, Texas January 20-22 ${ }^{\text {nd }}$.

Sarmiento JL., and Wofsy SC., (1996), Co-Chairs, A U.S. Carbon Cycle Science Plan, A

Report of the Carbon and Climate Working Group, US Global Change Research

Program, Washington, DC, pp 10.

Schimel D., D. Alves, I. Enting, M. Heimann, E. Joos, D. Raynaud and T. Wigley, (1996),

$\mathrm{CO}_{2}$ and the Carbon Cycle, in Climate Change 1995, vol. Edited by JT. Houghton,

LGM. Filbo, BA. Callander, N. Harris, A. Kattenberg and K. Maskell, 76-78, Cambridge University Press, Cambridge.

Wielopolski L., I. Orion, G. Hendrey and H Roger H., (2000) Soil Carbon Measurements

Using Inelastic Neutron Scattering, IEEE Trans. Nucl. Sciences, 47,914-917.

Wielopolslu L., S. Mitra, G. Hendrey,H. Rogers, A. Torbert and Prior S., (2003), Non-

Destructive In situ Soil Carbon Analysis: Principle and Results. Proceedings of the

Second Annual Conference on Carbon Sequestration, May 3-5, Article No. 225. 
Wielopolski L., S. Mitra, G. Hendrey, I. Orion, S. Prior, H. Rogers, B. Runion, A. Torbert, (2004) Won-destructive Soil Carbon Analyzer (ND - SCA)”, BNL Report N0.72200-2004.

Wielopolski L., Z. Song, I. Orion, AL. Hanson, and G. Hendrey, (In Press, 2004), Basic Considerations for Monte Carlo Calculations in Soil, Applied Radiation and Isotopes.

Tąylor HM., D.R. Upchurch, J.M. Brown, and H.H. Rogerss, "Some methods of root investigations". In "Plants Roots and Their Environment", Eds., B.L. McMichael and H. Persson. Elsevier Science Publisher B.V. 1991,pp. 553-564. 


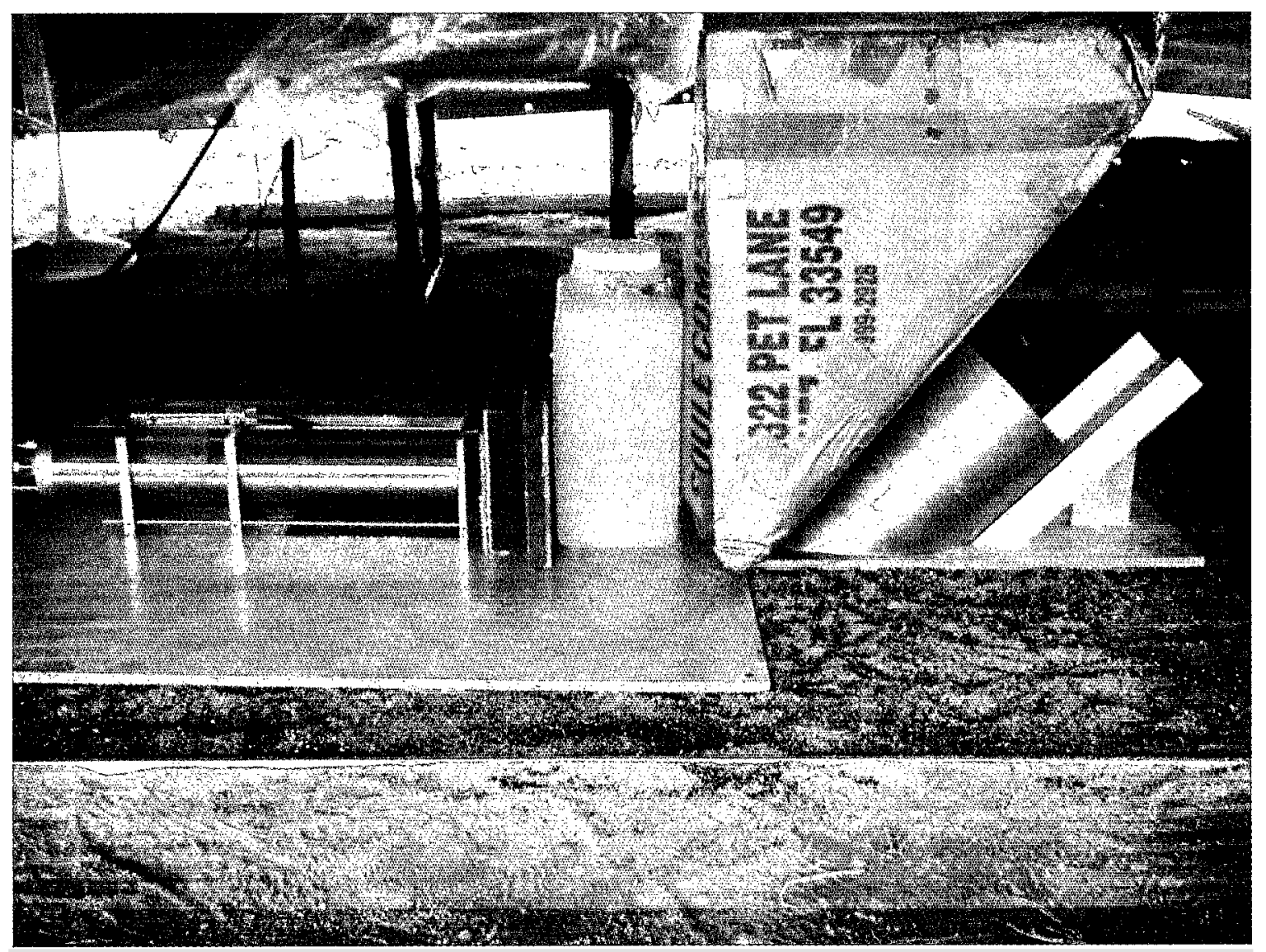

Figure 1. The original INS system placed on the ground of sandpit filled with sand and $10 \%$ carbon by weight. 


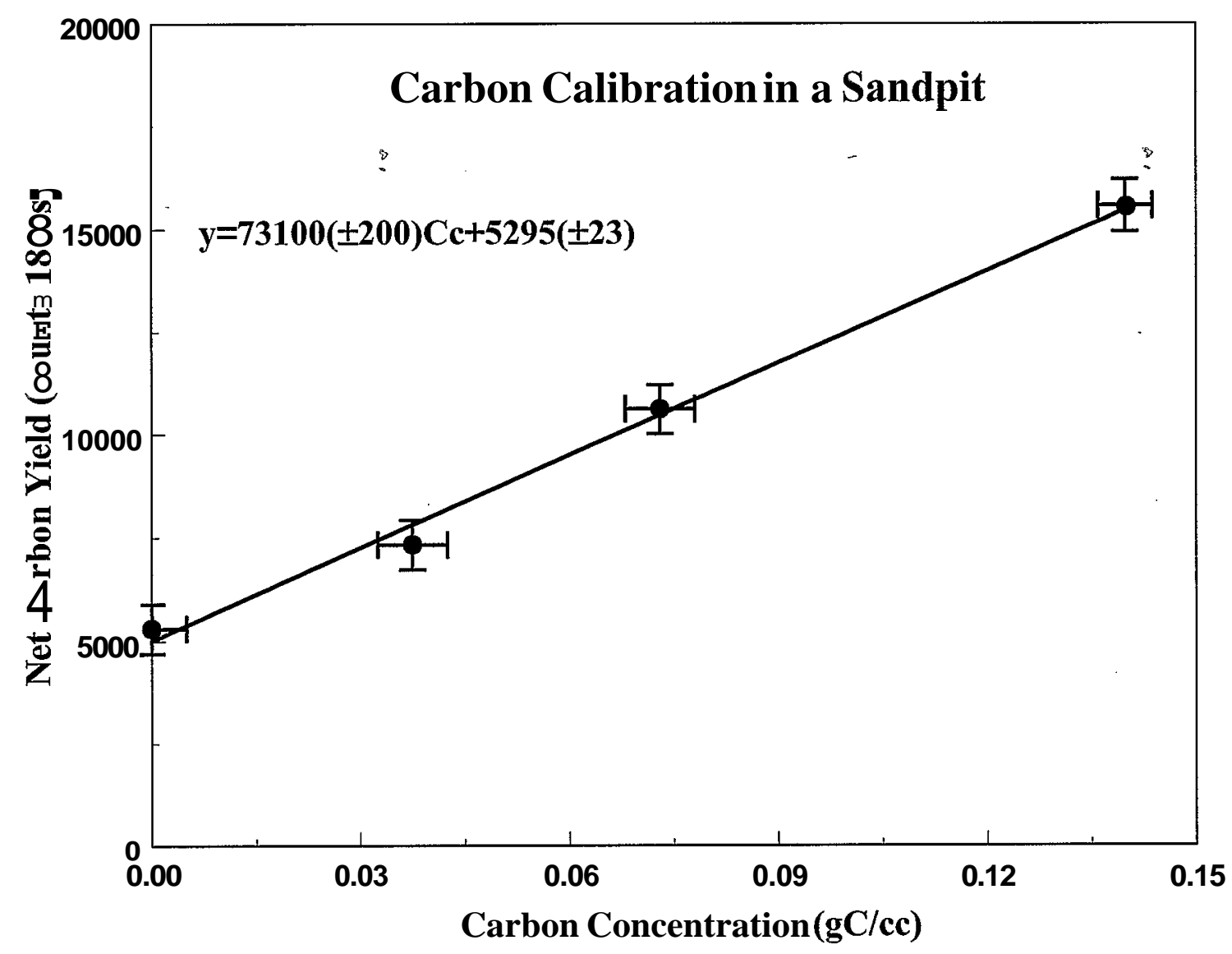

Figure 2. Calibration line of carbon in a sandpit at $0,2.5,5$, and $10 \%$ carbon by weight and soil bulk density $1.4 \mathrm{~g} / \mathrm{cc}$. 


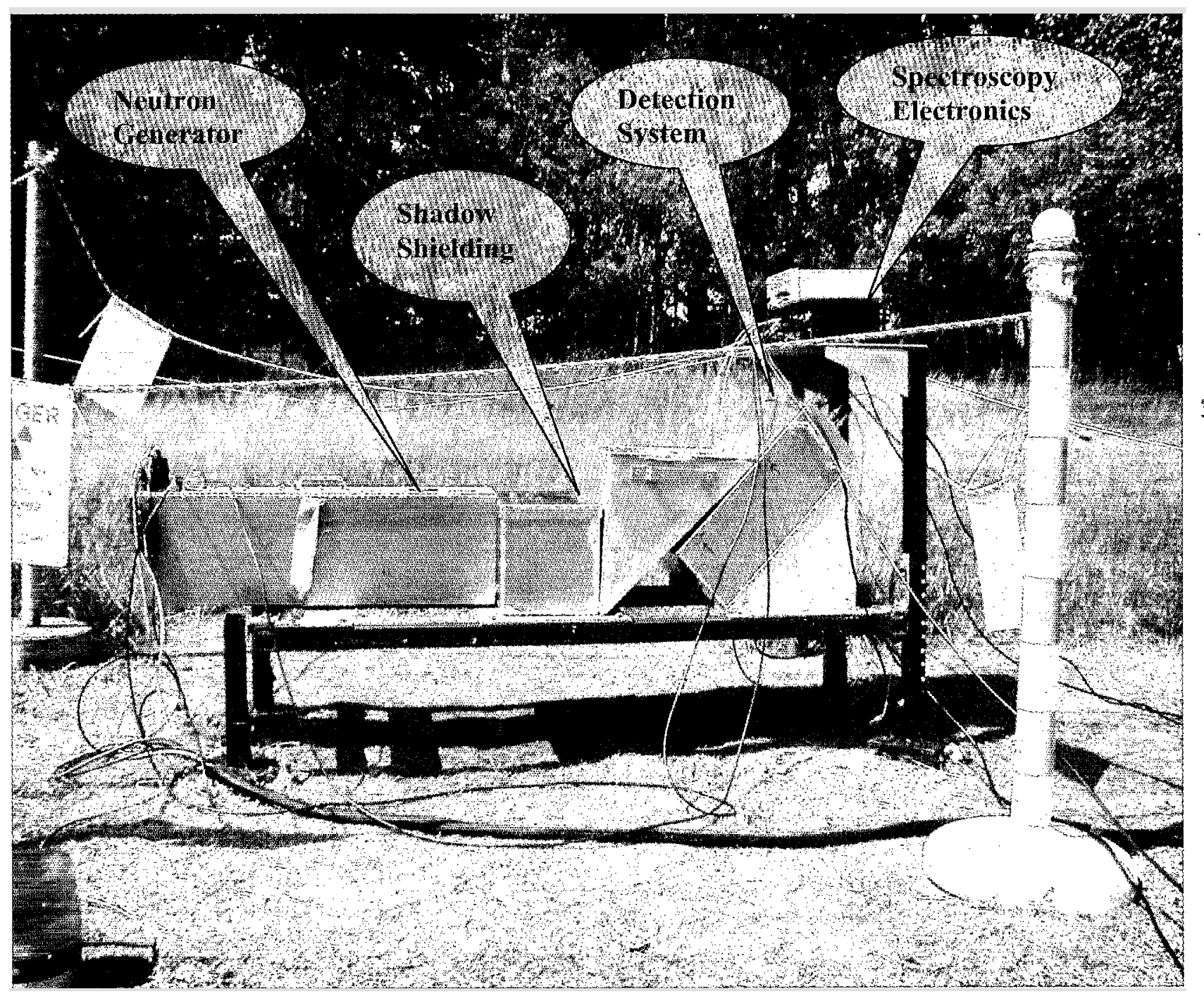

Figure 3. An INS system mounted on a stand for in-field stationary measurements. 


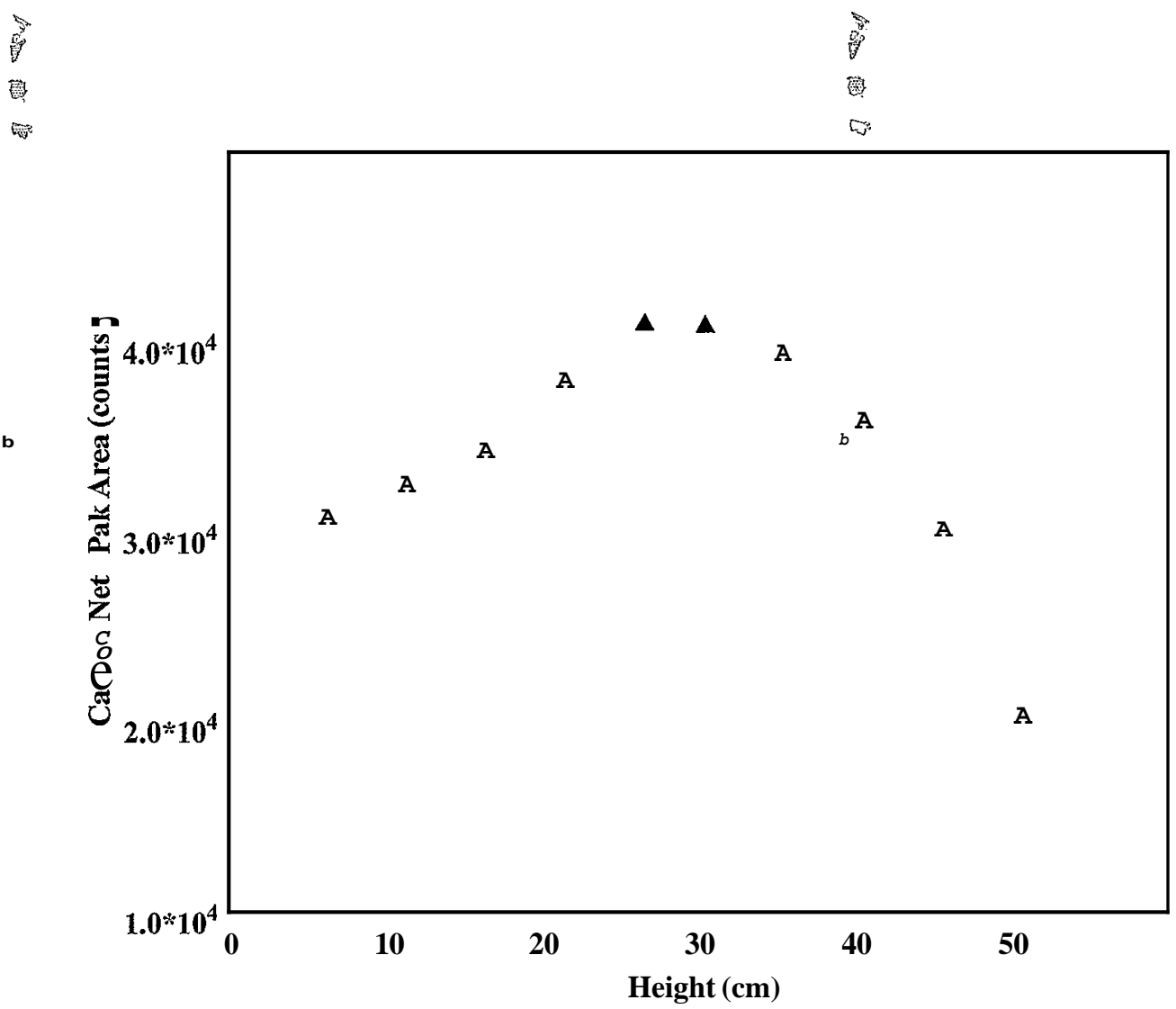

Figure 4. Net carbon yield as a function of the source and height of the detection system above the ground level. 


\section{Normalized Neutron Flux Distribution}

\section{Source $30 \mathrm{~cm}$ Above the Ground, Norm $=8842,10^{8}$ Histories}

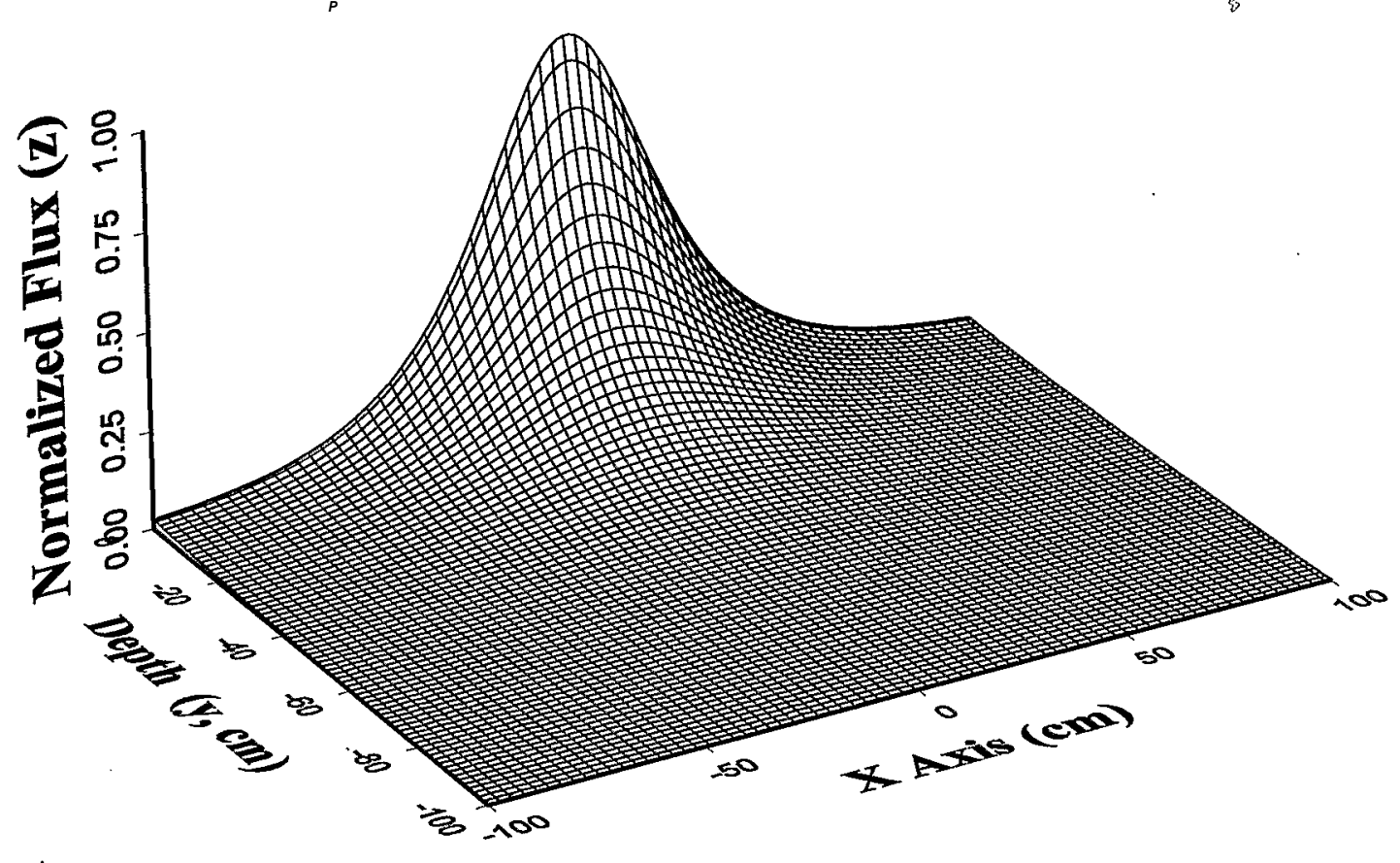

Figure 5. Three-dimensional display of the relative neutron flux in soil from a pointsource position $30 \mathrm{~cm}$ above the ground. The neutron flux is normalized at $(0,0)$. 


\section{Iso-Contours at $0.1,1.0,10,50,90 \%$ Levels} Neutron Source $30 \mathrm{~cm}$ Above the Ground

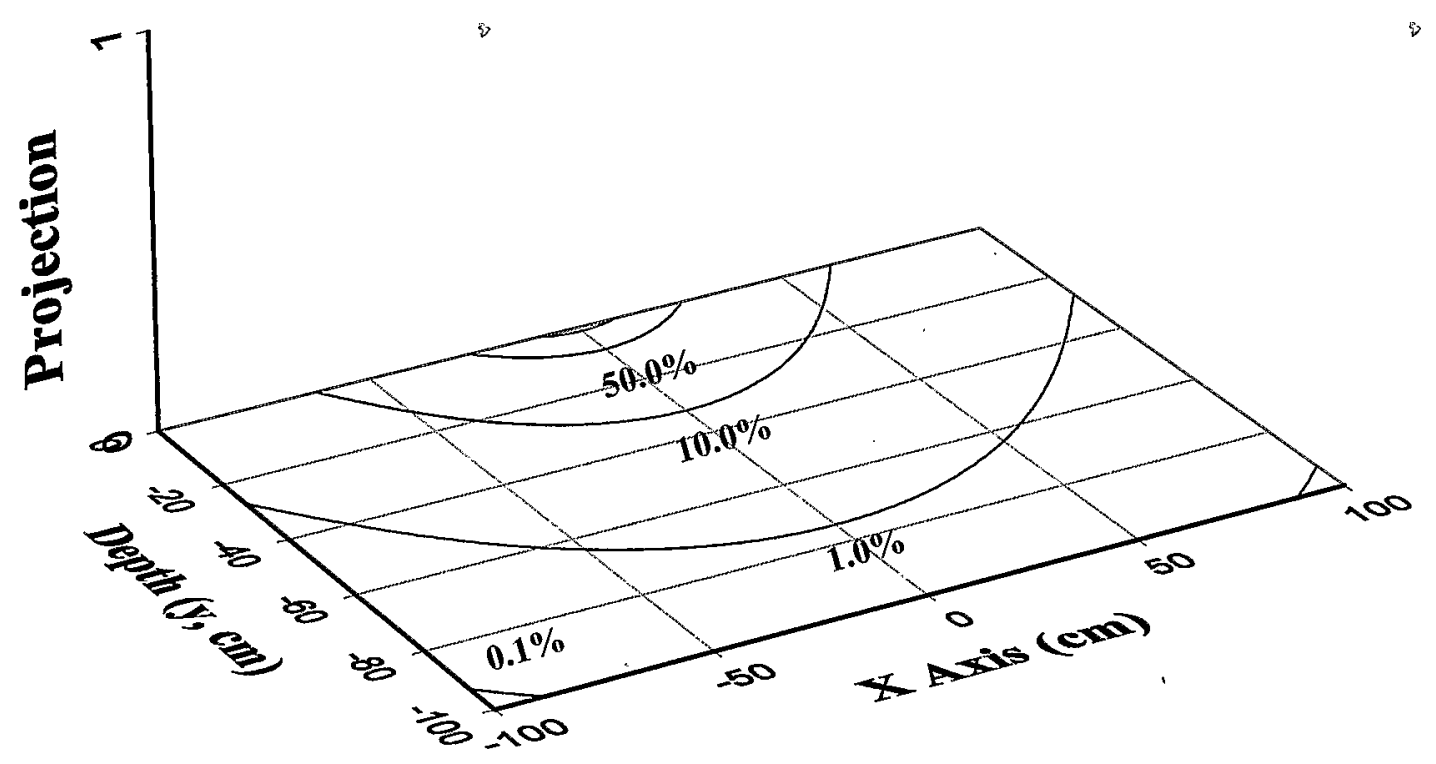

Figure 6. Isoflux contour lines at $0.1,1.0,10.0,50,90$ percent levels for a source $30 \mathrm{~cm}$ above the ground. 

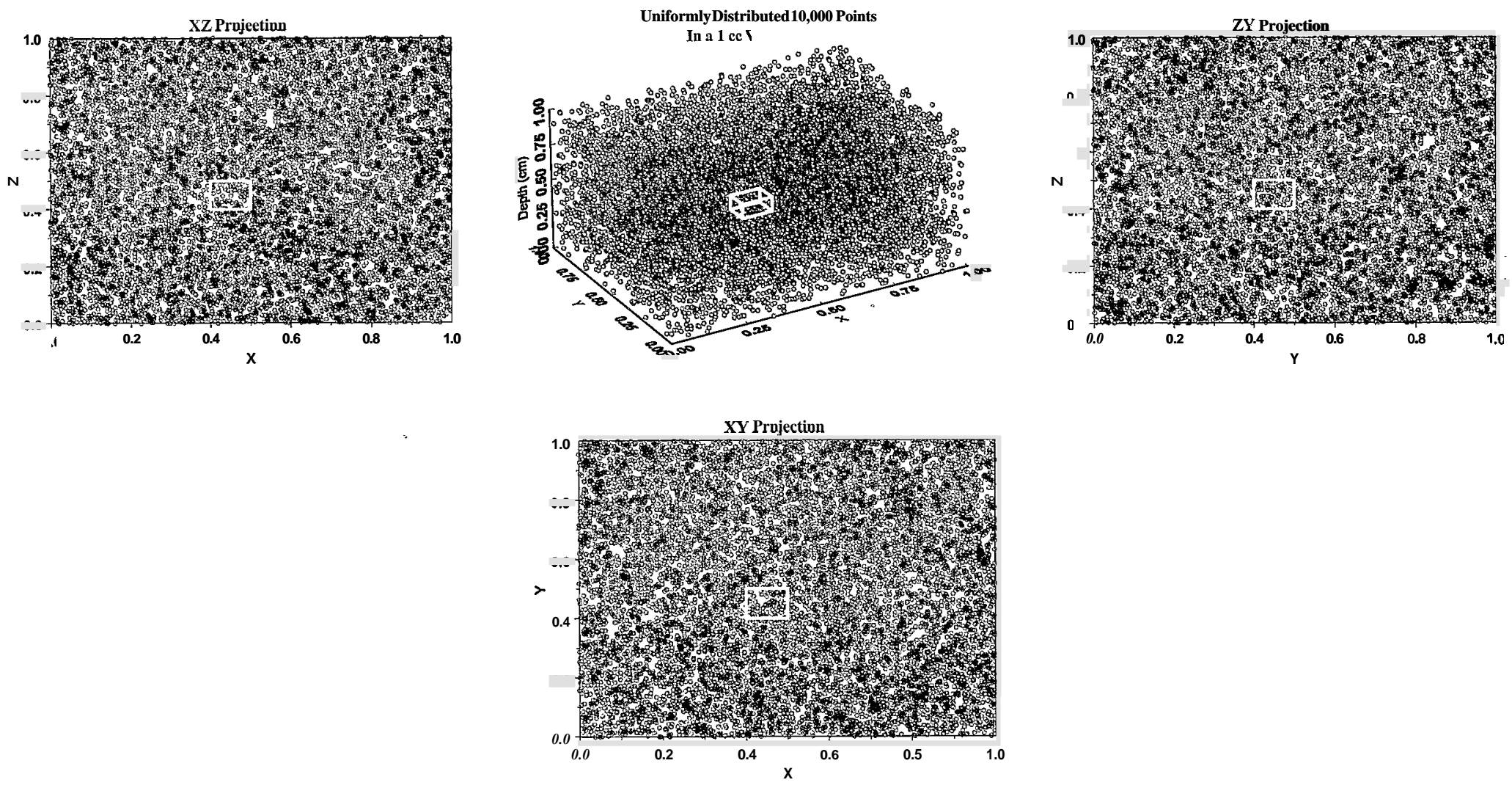

Figure 7. Ten thousand points uniformly distributed in a unit volume (center) and projection on each plane. The sampling volume is marked in the center of each panel. 
Uniformly in XY and Normally in $\mathrm{Z}$ Directions 10,000 Points in a 1 ce Volume
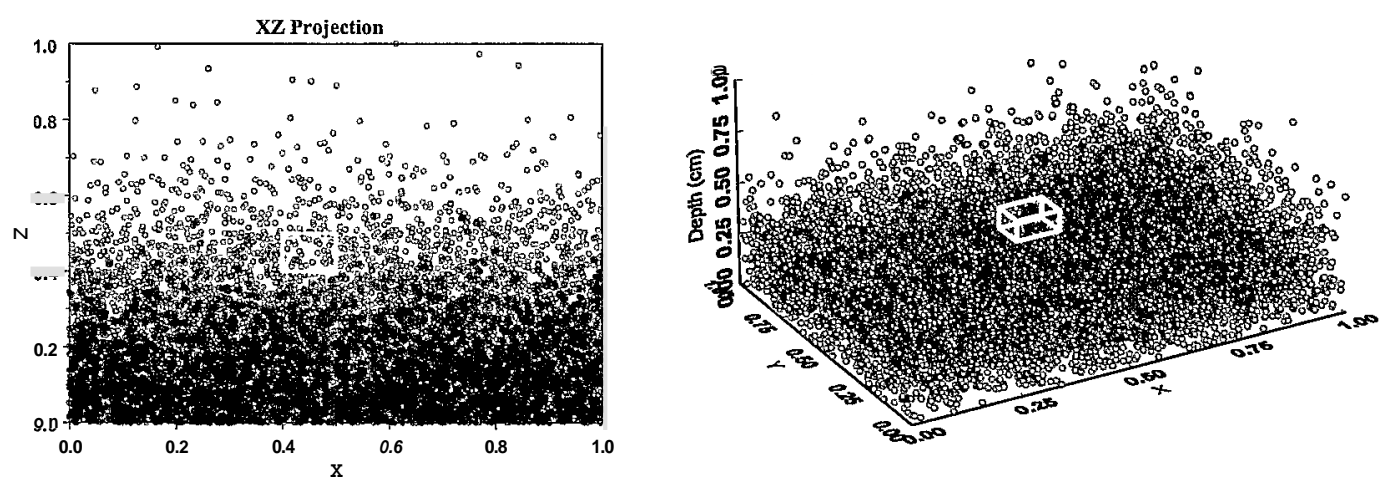

XY Projection

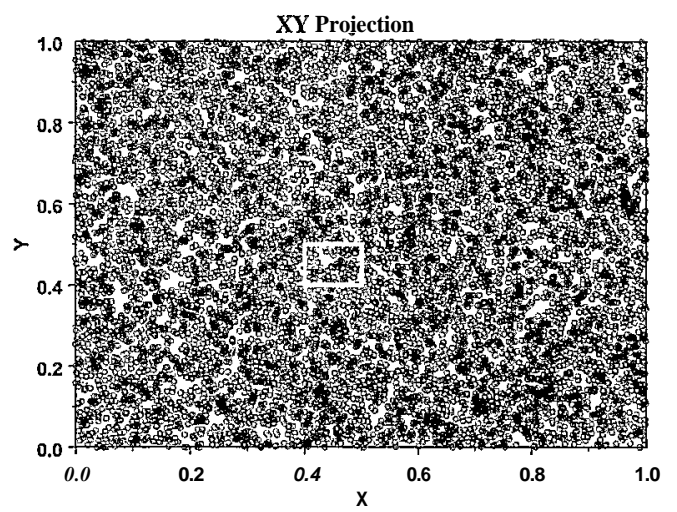

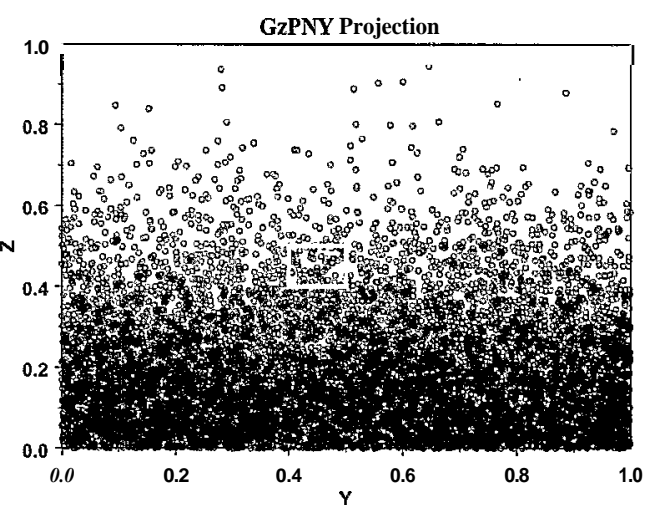

$\infty$

(6)

Figure 8. Ten thousand points uniformly distributed in the lateral directions and normally distributed with depth in a unit volume (center) and projection on each plane. The sampling volume is marked in the center of each panel. 


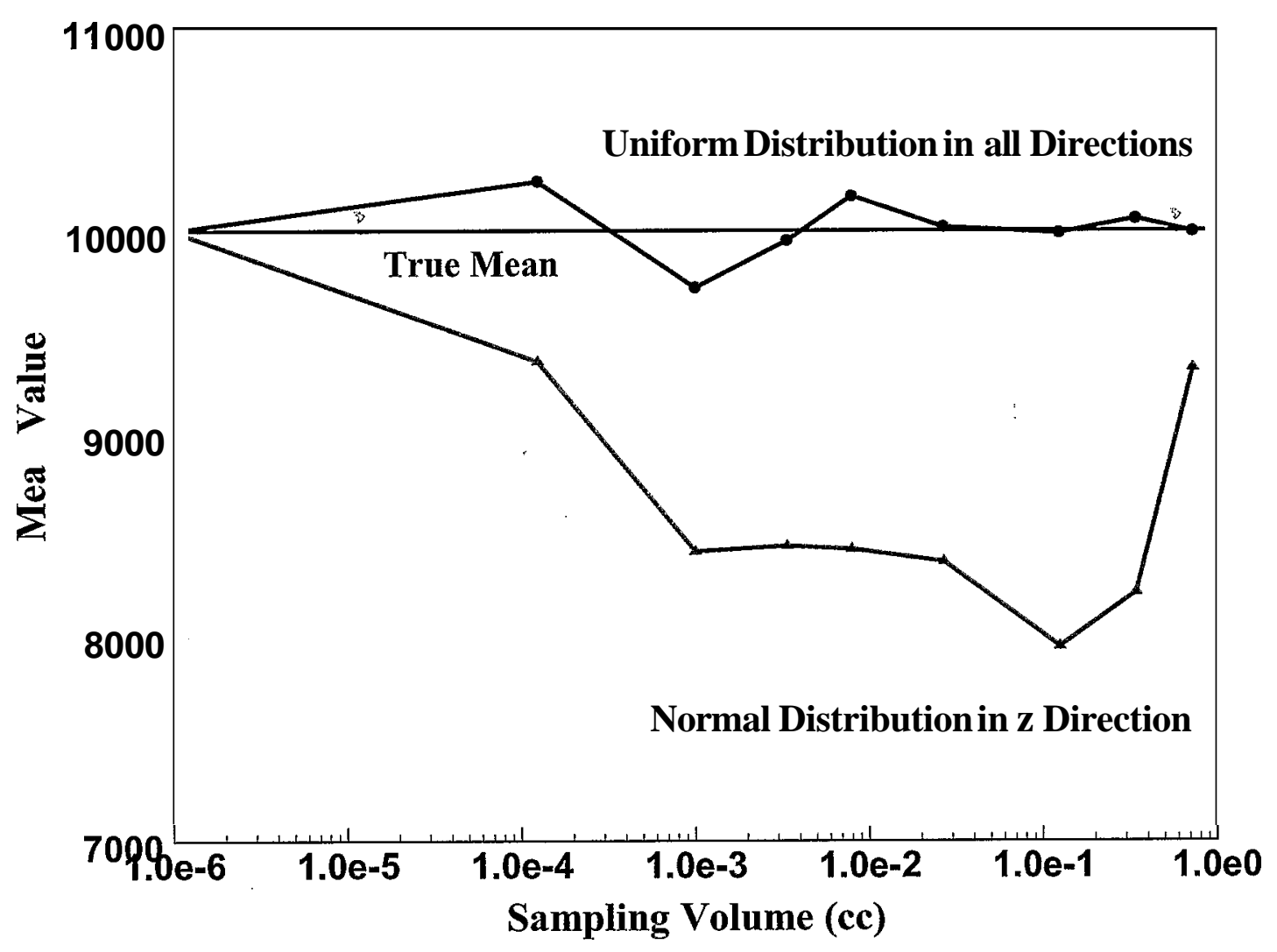

Figure 9. Variations in the estimates of the sampled mean values for uniform and normally distributed points. 


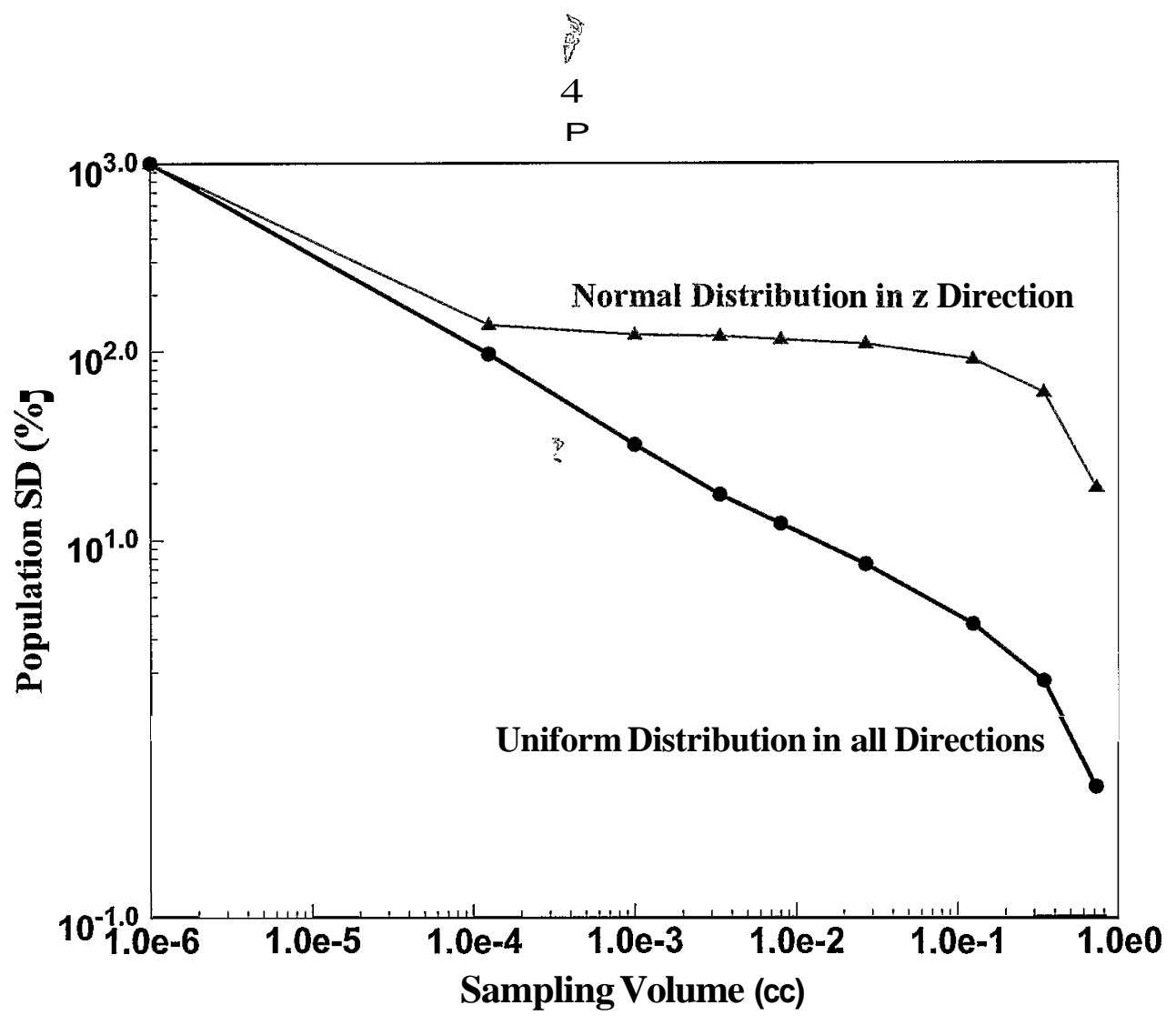

Figure 10. Variations in the estimates of the samples' standard variation (SD) values for uniform and normally distributed points. 